\title{
Doppler ultrasound evaluation in preeclampsia
}

\author{
Maria A Lopez-Mendez ${ }^{1,3}$, Victoria Martinez-Gaytan², Raul Cortes-Flores², Rene M Ramos-Gonzalez², \\ Mauro A Ochoa-Torres ${ }^{2}$, Idalia Garza-Veloz ${ }^{3}$, Monica I Martinez-Acuña ${ }^{3}$, Jose I Badillo-Almaraz ${ }^{3}$ \\ and Margarita L Martinez-Fierro ${ }^{3^{*}}$
}

\begin{abstract}
Background: Worldwide preeclampsia (PE) is the leading cause of maternal death and affects 5 to $8 \%$ of pregnant women. PE is characterized by elevated blood pressure and proteinuria. Doppler Ultrasound (US) evaluation has been considered a useful method for prediction of PE; however, there is no complete data about the most frequently altered US parameters in the pathology. The aim of this study was to evaluate the uterine, umbilical, and the middle cerebral arteries using Doppler US parameters [resistance index (RI), pulsatility index (PI), notch (N), systolic peak (SP) and their combinations] in pregnant women, in order to make a global evaluation of hemodynamic repercussion caused by the established PE.

Results: A total of 102 pregnant Mexican women (65 PE women and 37 normotensive women) were recruited in a cases and controls study. Blood velocity waveforms from uterine, umbilical, and middle cerebral arteries, in pregnancies from 24 to 37 weeks of gestation were recorded by trans-abdominal examination with a Toshiba Ultrasound Power Vision 6000 SSA-370A, with a $3.5 \mathrm{MHz}$ convex transducer. Abnormal general Doppler US profile showed a positive association with PE [odds ratio $(\mathrm{OR})=2.93,95 \%$ confidence interval $(\mathrm{Cl})=1.2-7.3, P=0.021)$ ], and a specificity and predictive positive value of $89.2 \%$ and $88.6 \%$, respectively. Other parameters like N presence, RI and PI of umbilical artery, as well as the PI of middle cerebral artery, showed differences between groups ( $P$ values $<0.05)$.
\end{abstract}

Conclusion: General Doppler US result, as well as N from uterine vessel, RI from umbilical artery, and PI from umbilical and middle cerebral arteries in their individual form, may be considered as tools to determine hemodynamic repercussion caused by PE.

Keywords: Doppler velocimetry, Preeclampsia, Uterine artery, Umbilical artery, Middle cerebral artery

\section{Background}

Worldwide pre-eclampsia (PE) is the first cause of maternal mortality, intrauterine growth retardation (IUGR), and fetal prematurity [1,2]. PE affects $5-10 \%$ of pregnancies and is clinically manifested after 20 weeks of gestation (GW) $[3,4]$. The etiology of PE is still unknown, although an excessive maternal systemic inflammatory response and an imbalance between circulating angiogenic and anti-angiogenic factors have been described $[5,6]$. The pathophysiology of PE is based on the incapability of the trophoblast to invade properly the myometrium causing a limited remodeling of spiral arteries [7]. The impaired placental perfusion caused by vascular abnormalities precedes clinical manifestations

\footnotetext{
* Correspondence: margaritamf@uaz.edu.mx

${ }^{3}$ Molecular Medicine Laboratory, Unidad Academica de Medicina Humana y Ciencias de la Salud, Universidad Autonoma de Zacatecas, Carretera Zacatecas-Guadalajara Km. 6, C.P. 98160 Zacatecas, Mexico

Full list of author information is available at the end of the article
}

of PE and it can be detected by Doppler ultrasound (US). The latter has been considered a useful method for prediction of PE and adverse pregnancy outcome $[8,9]$. Uterine artery is the most studied vessel in the Doppler evaluation in PE, because it represents the maternal vascular condition, through the pulsatility and resistance index (PI and RI respectively) and the presence of early diastolic notch $(\mathrm{N})[10,11]$. Although there are some studies including the umbilical artery as a relevant vessel in the PE evaluation, traditionally this artery is taken together with the middle cerebral artery in the fetus status evaluation [12-15]. In PE evaluation using Doppler US, there is no complete data about the most frequently altered US parameters in their individual or combined form for each artery. In this study we evaluate the uterine, umbilical, and the middle cerebral arteries using several Doppler US parameters (RI, PI, N, SP and their combinations) in order to make a global evaluation of hemodynamic

\section{Biomed Central}

(c) 2013 Lopez-Mendez et al.; licensee BioMed Central Ltd. This is an open access article distributed under the terms of the Creative Commons Attribution License (http://creativecommons.org/licenses/by/2.0), which permits unrestricted use, distribution, and reproduction in any medium, provided the original work is properly cited. 
repercussion caused by the established PE, in a cases and controls study.

\section{Methods \\ Patients}

The patients were recruited from the high risk consult of the Unidad Medica de Alta Especialidad (UMAE) \# 23 of the Instituto Mexicano del Seguro Social (IMSS) in Monterrey, Mexico, between September 2009 and June 2010.Women from 15 to 40 years old, with singleton pregnancy between the 24-37 GW were included and divided in cases and controls groups. The cases group consisted by diagnosed PE women according to the guidelines of the International Society for the Study of Hypertension in Pregnancy [16]. Most of the patients were not on any treatment at the time of examination, the patients from the cases group with treatment, had been on it for less than 2 days. Medical therapy of these patients was selected according to the Mexican Technical Guideline for Prevention, Diagnosis, and Management of Preeclampsia-Eclampsia [17]. Normotensive women from the control group did not have any hypo tensor treatment at the moment of the US, nor did they have co-morbidities associated to IUGR. Multiple pregnancies, pregnancies with structural or chromosomal fetus malformations, no feasibility to undergo the Doppler US test (obesity, oligohydramnios, etc.) were excluded from the study. The protocol was approved by the Institutional Review Board (ID number R-2010-1905-17). All patients provided written informed consent for their participation.

\section{Doppler US evaluation}

To determine the Doppler US pattern, only one exam on each patient was carried out at the recruitment time. The Doppler US was performed by trans-abdominal examination with a Toshiba Power Vision 6000 SSA$370 \mathrm{~A}$ model, with a $3.5 \mathrm{MHz}$ convex transducer. The examination included one uterine artery from the placental side or the mean if there was a symmetrical placenta, the umbilical artery, and one middle cerebral artery (indistinct hemisphere) $[18,19]$. Umbilical artery measures were taken in a free umbilical cord loop. In order to register the values, four out of five spectral continuous and identical waves were considered, after verification of regular maternal and fetal cardiac frequency, without breath and/or fetal movement interference. The Doppler insonation angle was maintained below 60 degrees. All the US evaluations were performed by a gynecologist with maternal-fetal medicine experience. The results were documented on a record sheet designed for the study, as well as in the clinical record of each patient. The abnormality in the wave morphology was considered as the presence of a protodiastolic $\mathrm{N}$ after the $24 \mathrm{GW}$ in the uterine artery [20]. RI and PI values above the $95^{\text {th }}$ percentile standardized for the gestational age were considered abnormal for the uterine and umbilical arteries, and below the $10^{\text {th }}$ percentile for the middle cerebral artery $[20,21]$. Alterations in any of the uterine artery parameters were interpreted as an abnormal result of this artery and consequently an abnormal general Doppler result was reported. In the umbilical vessel, alterations in the individual or combined RI and PI values were reported as an abnormal artery result. Decreases of individual RI or PI values, as well as their combination in the middle cerebral artery were considered as an abnormal artery result. For umbilical and middle cerebral vessels only their combination with another abnormal artery was considered to report an abnormal general Doppler result.

\section{Statistical analysis}

Chi-square or Fisher's exact test was used to analyze categorical variables. Unpaired $t$-test and Mann-Whitney Rank Sum test were used for continuous variables; $P$ values were corrected by maternal age using a multiple logistic regression analysis. Sensitivity, specificity, predictive positive (PPV) and negative (NPV) values were calculated according to the Bayes theorem. Statistically, $P$ values $<0.05$ were considered significant. Statistical analysis was performed using the SigmaPlot software v11.

\section{Results}

A total of 102 Mexican women were recruited and sub-divided in two groups: 65 formed the cases group (38 mild and 27 severe PE) and 37 were the control group. $56.9 \%$ of the cases were diagnosed with PE before $34 \mathrm{GW}$ (early PE) and the remaining $43.1 \%$ had a late onset of disease (34-37 GW). General characteristics of the study population are shown in Table 1 . The median of GW was 34 for the cases (ranging from 24.5 to $37 \mathrm{GW}$ ) and 32 (ranging from 24 to $37 \mathrm{GW}$ ) for controls, respectively. Maternal age, was the only characteristic with statistical difference among groups (29.1 for the cases and 26.1 for the controls, $P=0.019)$. There were no differences in risk factors such as past personal or familial history of PE, primipaternity and nulliparity, among study groups (Table 1 ).

Table 2 summarizes the ultrasound findings classified by artery and its comparison between cases and controls. The proportion of patients with PE and an abnormal Doppler US for the uterine artery was statistically significant $(\mathrm{OR}=2.6,95 \% \mathrm{CI}=1.01-6.68, P=0.047)$. The $\mathrm{N}$ presence was restricted only for the cases group in a proportion of $20 \%(\mathrm{OR}=9.0,95 \% \mathrm{CI}=1.127-71.887, P=0.032)$. The medians of RI and PI parameters of the uterine artery showed a close gap between the study groups and therefore they were not associated to PE ( $P$ values $>0.05)$. The median of umbilical RI and PI were 0.59 and 0.91 for the cases group and 0.51 and 0.78 for the control group, respectively. There was a positive association between individual values 
Table 1 Comparison of general characteristics between study groups

\begin{tabular}{|c|c|c|c|}
\hline Characteristic & $\begin{array}{c}\text { PE } \\
(n=65)\end{array}$ & $\begin{array}{l}\text { Controls } \\
(n=37)\end{array}$ & $P$ value \\
\hline Maternal age years, mean (range) & $29.1(15-42)$ & $26.1(17-36)$ & $0.019^{*}$ \\
\hline Gestational age weeks, median (range) & $34(24.5-37)$ & $32(24-37)$ & 0.084 \\
\hline Number of pregnancies, median (range) & $2(1-9)$ & $2(1-6)$ & 0.608 \\
\hline Past history of PE, n (\%) & $10(15.4)$ & $1(2.7)$ & 0.098 \\
\hline Familial history of PE, n (\%) & $9(13.8)$ & $1(2.7)$ & 0.141 \\
\hline Primipaternity n (\%) & $24(36.9)$ & $11(29.7)$ & 0.604 \\
\hline Nulliparous, n (\%) & $26(40.0)$ & $11(29.7)$ & 0.410 \\
\hline Blood pressure systolic, median (range) & $140(130-179)$ & $100(90-122)$ & $<0.001$ \\
\hline Blood pressure diastolic, median (range) & $90(50-120)$ & $70(50-80)$ & $<0.001$ \\
\hline
\end{tabular}

"Statistical significance.

of abnormal umbilical RI or PI and PE (OR $=30.63$, $95 \% \mathrm{CI}=1.47-639.71, P=0.027$, and $\mathrm{OR}=10.82,95 \%$ $\mathrm{CI}=2.19-53.58, P=0.004$, respectively); however, considering the general Doppler result for this artery, differences between proportions of abnormal umbilical Doppler US in the study groups were not observed $(P=0.107)$. An abnormal PI was the only middle cerebral artery parameter associated to $\mathrm{PE}(\mathrm{OR}=0.243,95 \%$ $\mathrm{CI}=0.08-0.70, P=0.009$ ).

Figure 1 shows the frequencies of the most common abnormal US findings, including the parameters combinations for each artery. In the uterine artery, the most frequent abnormal parameter in its individual form and the most frequent abnormal combination for both the cases and controls were the RI (17\% for cases and 6.9\% for controls) and the RI + PI (31\% for cases and 3.4\% for controls) respectively. The $\mathrm{N}$ presence and its combination with altered RI $(\mathrm{RI}+\mathrm{N})$ and the combination between abnormal RI, PI and $\mathrm{N}(\mathrm{RI}+\mathrm{PI}+\mathrm{N})$, only had representation in the cases group.
In the umbilical artery the most frequent altered parameter was the RI (17\% in the cases group and $4 \%$ for the controls). The combination of abnormal RI + PI was detected in 65.2\% of the cases with abnormal Doppler US for this artery versus $8.7 \%$ of the control pregnancies. Considering the abnormal middle cerebral artery results, $53.8 \%$ of women showed altered PI and SP individual parameters in the cases group; this condition was present only in $3.2 \%$ of the controls.

Table 3 displays the Doppler US parameters ability to classify the study groups. The general Doppler result had the most representative values with specificity and PPV of $75.7 \%$ and $78.6 \%$, respectively. The sensitivity and the NPV for the general US examination were calculated in $50.8 \%$ and $46.7 \%$, respectively.

\section{Discussion}

Most of reports related to PE evaluation by Doppler US have been focused on the study of the uterine artery and

Table 2 Classification of Doppler US findings by artery in the study groups

\begin{tabular}{|c|c|c|c|c|}
\hline Artery & Ultrasound finding & $\begin{array}{c}\text { PE } \\
(n=65)\end{array}$ & $\begin{array}{l}\text { Controls } \\
(n=37)\end{array}$ & $P$ value $^{\dagger}$ \\
\hline \multirow{4}{*}{ Uterine } & Rl, median (range) & $0.54(0.2-1)$ & $0.51(0.31-0.62)$ & 0.131 \\
\hline & Pl, median (range) & $0.84(0.42-1.7)$ & $0.79(0.44-1.9)$ & 0.510 \\
\hline & Notch proportion (\%) & 20 & 0.0 & $0.032^{*}$ \\
\hline & Uterine abnormal Doppler US proportion (\%) & 44.6 & 21.6 & $0.047^{*}$ \\
\hline \multirow{3}{*}{ Umbilical } & Rl, median (range) & $0.59(0.31-1.1)$ & $0.51(0.28-0.76)$ & $0.027^{*}$ \\
\hline & Pl, median (range) & $0.91(0.42-1.9)$ & $0.78(0.35-1.26)$ & $0.004^{*}$ \\
\hline & Umbilical abnormal Doppler US proportion (\%) & 49.2 & 29.7 & 0.107 \\
\hline \multirow{5}{*}{ Middle cerebral } & Rl, median (range) & $0.76(0.5-1)$ & $0.83(0.4-1.3)$ & 0.500 \\
\hline & Pl, median (range) & $1.4(0.9-2.66)$ & $1.815(1.11-2.81)$ & $0.009^{*}$ \\
\hline & SP, mean (range) & $0.462(0.22-0.80)$ & $0.434(0.18-0.60)$ & 0.218 \\
\hline & Cerebral abnormal Doppler US proportion (\%) & 23.1 & 18.9 & 0.911 \\
\hline & Proportion of Abnormal Doppler US (\%) & 47.7 & 24.3 & $0.021^{*}$ \\
\hline
\end{tabular}

${ }^{\dagger} P$ value adjusted by maternal age. "Statistical significance. 


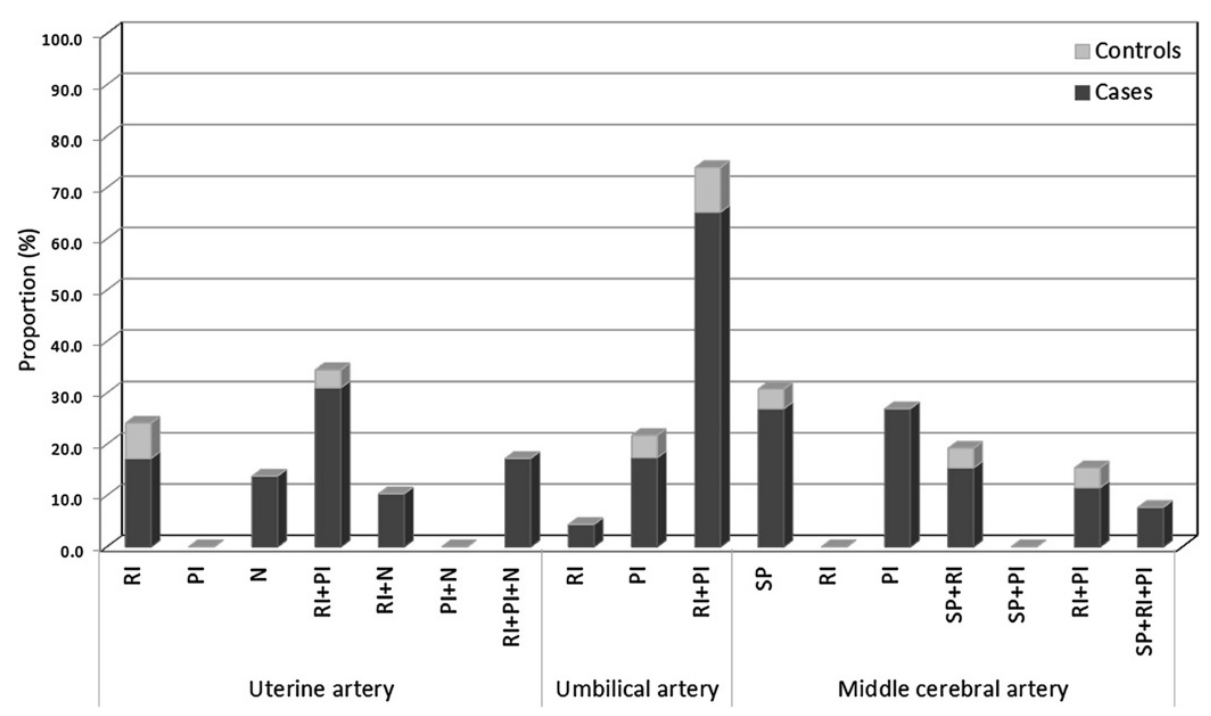

Figure 1 Proportions of the most common abnormal US findings and their combinations for each artery.

its parameters [22-24]; there are descriptive trials about the hemodynamic changes during pregnancy [25], studies to determine the normality ranges of the Doppler US values in some populations [26,27], and reports in which the aim has been to get a spectral pattern of Doppler US to predict which pregnancies will evolve to PE [28-31]. Only a few papers provide an extended description of other vessels in PE evaluation, and even fewer have shown the combination of two or more arteries with the objective of establishing a more informative and accurate report [32-35]. In this study, we report a full Doppler US vision about PE induced vascular changes in the mother, reflected as vascular changes in the uterine artery, and in the fetus, considered as alterations in umbilical and middle cerebral artery parameters; additionally, these abnormal Doppler US measurements were disaggregated for each examined vessel.

In our study, maternal age was the only known PE risk factor with differences among groups [36,37]. Despite

Table 3 Effectiveness of Doppler US in PE discrimination: accuracy of general Doppler US result by artery and their combinations

\begin{tabular}{|c|c|c|c|c|c|}
\hline Artery & Parameter & Sensitivity (\%) & Specificity (\%) & $\mathrm{PPV}^{\dagger}(\%)$ & $\mathrm{PNV}^{\ddagger}(\%)$ \\
\hline \multirow{7}{*}{ Uterine } & $\mathrm{Rl}$ & 7.7 & 94.6 & 71.4 & 36.8 \\
\hline & N & 6.2 & 100.0 & 100.0 & 37.8 \\
\hline & $\mathrm{RI}+\mathrm{Pl}$ & 13.8 & 97.3 & 90.0 & 39.1 \\
\hline & $\mathrm{Rl}+\mathrm{N}$ & 4.6 & 100.0 & 100.0 & 37.4 \\
\hline & $\mathrm{RI}+\mathrm{Pl}+\mathrm{N}$ & 7.7 & 100.0 & 100.0 & 38.1 \\
\hline & Abnormal Doppler US of uterine artery & 44.6 & 78.4 & 78.4 & 44.6 \\
\hline & $\mathrm{Rl}$ & 1.5 & 100.0 & 100.0 & 36.6 \\
\hline \multirow{2}{*}{ Umbilical } & $\mathrm{Pl}$ & 6.2 & 97.3 & 80.0 & 37.1 \\
\hline & $\mathrm{Rl}+\mathrm{Pl}$ & 23.1 & 94.6 & 88.2 & 41.2 \\
\hline \multirow{8}{*}{ Middle Cerebral } & Abnormal Doppler US of umbilical artery & 49.2 & 70.3 & 74.4 & 44.1 \\
\hline & $\mathrm{Rl}$ & 10.8 & 100.0 & 100.0 & 38.9 \\
\hline & SP & 10.8 & 97.3 & 87.5 & 38.3 \\
\hline & $\mathrm{PI}+\mathrm{SP}$ & 6.2 & 97.3 & 80.0 & 37.1 \\
\hline & $\mathrm{RI}+\mathrm{Pl}$ & 1.5 & 91.9 & 25.0 & 34.7 \\
\hline & $S P+R I+P I$ & 3.1 & 100.0 & 100.0 & 37.0 \\
\hline & Abnormal Doppler US of cerebral artery & 23.1 & 81.1 & 68.2 & 37.5 \\
\hline & Abnormal Doppler US & 50.8 & 75.7 & 78.6 & 46.7 \\
\hline
\end{tabular}

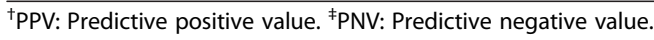


the fact that nulliparity, personal history and/or family of PE have been supported as PE risk factors in several studies $[38,39]$, our results showed no association between these characteristics and PE; however, these data should be cautiously interpreted due to the small number of patients included in the study.

Considering the Doppler US findings for motherhood status, from individual parameters evaluated in the uterine artery, $\mathrm{N}$ showed to be the most meaningful (but not the most frequent) individual finding, due to the fact that its presence was restricted to the cases group. These results are similar to those reported previously, where the $\mathrm{N}$ is considered as a relevant parameter in the uterine artery study $[40,41]$. Although PI and RI are considered fundamental values in the uterine artery evaluation, we did not find differences in these parameters among the study groups. It could be because the reference values considered in previous studies consisted of standardized measures for each population, and the abnormality limits of these values may differ between populations [40].

In the fetal condition, the umbilical artery has been related typically to pregnancy outcome, while the middle cerebral artery has been considered as a fetal circulation marker and a useful non-invasive tool in risk assessment for fetal anemia [42-45]. In our study, as individual measurements, abnormal RI from umbilical artery, and altered PI from umbilical and middle cerebral arteries, were associated to PE; however, considering all the parameters reviewed in these arteries, the general results for each vessel did not show a difference between groups, suggesting that these individual parameters, but not the general Doppler US for these arteries, could be considered as indicators to evaluate the specific $\mathrm{PE}$ vascular alterations.

Even though PE prediction was not the aim of this study, the capability of Doppler assessment to classify correctly the study groups was determined using individual parameters and their combinations. In general, individual or combined measurements showed high specificity and PPV, conversely to the low sensitivity and NPV. Our findings reflected a wide gradient in the specificity/ sensitivity results with a screening parameter-dependent variation that may explain the conflicting results in the diagnostic accuracy of Doppler flow velocity to predicting PE in the previous reports. On the other hand, these results provide new information about the relevant US indicators for the pathology and it could contribute to generate more descriptive and accurate reports during the PE evaluation using Doppler assessment. In Mexico, there are no reports about the Doppler US features for the three arteries in the PE evaluation; our results provide evidence about the possibilities to select better and specific measurements of each vessel in future early $\mathrm{PE}$ Doppler US screenings.

\section{Conclusion}

General Doppler US result, as well as $\mathrm{N}$ from uterine vessel, RI from umbilical artery, and PI from umbilical and middle cerebral arteries in their individual form, may be considered as tools to determine hemodynamic repercussion caused by $\mathrm{PE}$.

\section{Abbreviations}

PE: Preeclampsia; US: Ultrasound; RI: Resistance index; PI: Pulsatility index; N: Notch; SP: Systolic peak; IUGR: Intrauterine growth retardation; GW: Weeks of gestation; PPV: Predictive positive value; NPV: Negative predictive value.

\section{Competing interests}

The authors declare that they have no competing interests. The authors are responsible for the content and writing of the research paper.

\section{Authors' contributions}

MALM, MLMF, drafted the manuscript. MALM, VMG, RCF, RMRG, MAOT, and MLMF, participated in the design of the study and in the coordination of the patients' recruitment. MALM, VMG, RCF, RMRG, MAOT, IGV, MIMA, and JIBA, participated in data acquisition, data analysis and interpretation, they participated in manuscript review. MLMF conceived of the study, and participated in its design and coordination, and performed the statistical analysis. All authors read and approved the final manuscript.

\section{Acknowledgments}

We thank all the study participants. Also, the authors gratefully acknowledge the critical reading and correction of this manuscript by María Guadalupe Ramos del Hoyo, M.E. This study was funded by FOMIX CONACyT-Gobierno del Estado de Zacatecas Grant (ID number: 121535).

\section{Author details}

${ }^{1}$ Departamento de Radiologia e Imagen, Unidad Medica de Alta Especialidad No. 25 Instituto Mexicano del Seguro Social, Monterrey, Mexico. ${ }^{2}$ Unidad Medica Materno-Fetal del Noreste, Unidad Medica de Alta Especialidad No. 23 Instituto Mexicano del Seguro Social, Monterrey, Mexico. ${ }^{3}$ Molecular Medicine Laboratory, Unidad Academica de Medicina Humana y Ciencias de la Salud, Universidad Autonoma de Zacatecas, Carretera

Zacatecas-Guadalajara Km. 6, C.P. 98160 Zacatecas, Mexico.

Received: 2 August 2013 Accepted: 15 November 2013

Published: 19 November 2013

\section{References}

1. Crispi F: Predictive value of angiogenic factors and uterine artery doppler for early- versus late-onset pre-eclampsia and intrauterine growth restriction. Ultrasound Obstet Gynecol 2008, 31:303-309.

2. Diab AE, Manal ME-B, Moustafa AE, Amal ES: Angiogenic factors for the prediction of pre-eclampsia in women with abnormal midtrimester uterine artery doppler velocimetry. Int J Gynaecol Obstet 2008, 102:146-151.

3. Baumwell S: Pre-eclampsia: clinical manifestations and molecular mechanisms. Nephron Clinical practice 2007, 106:C72-c81.

4. Backes $\mathrm{CH}$, Markham K, Moorehead P, Cordero L, Nankervis CA, Giannone PJ: Maternal preeclampsia and neonatal outcomes. J Pregnancy 2011, 2011:214365.

5. Szarka A, Rigo J Jr, Lazar L, Beko G, Molvarec A: Circulating cytokines, chemokines and adhesion molecules in normal pregnancy and preeclampsia determined by multiplex suspension array. BMC Immunol 2010, 11:59.

6. Molvarec A, Szarka A, Walentin S, Szucs E, Nagy B, Rigo J Jr: Circulating angiogenic factors determined by electrochemiluminescence immunoassay in relation to the clinical features and laboratory parameters in women with pre-eclampsia. Hypertens Res 2010, 33:892-898.

7. Davison JM, Homuth V, Jeyabalan A, Conrad KP, Karumanchi SA, Quaggin S, Dechend R, Luft FC: New aspects in the pathophysiology of preeclampsia. J Am Soc Nephrol 2004, 15:2440-2448.

8. Romero-Arauz JF R-LJ, Rivera-Velásquez P, Alvarez-Jimenez G, Molina-Pérez CJ: Velocimetría doppler de la arteria umbilical y resultado perinatal adverso en preeclampsia severa. Ginecologia y Obstetricia de Mexico 2008, 76:440-449. 
9. Yu J, Shixia CZ, Wu Y, Duan T: Inhibin A, activin A, placental growth factor and uterine artery doppler pulsatility index in the prediction of pre-eclampsia. Ultrasound Obstet Gynecol 2011, 37:528-533.

10. Gomez O, Martinez JM, Figueras F, Del Rio M, Borobio V, Puerto B, Coll O, Cararach V, Vanrell JA: Uterine artery doppler at 11-14 weeks of gestation to screen for hypertensive disorders and associated complications in an unselected population. Ultrasound Obstet Gynecol 2005, 26:490-494.

11. Schwarze A, Nelles I, Krapp M, Friedrich M, Schmidt W, Diedrich K, Axt-Fliedner R: Doppler ultrasound of the uterine artery in the prediction of severe complications during low-risk pregnancies. Arch Gynecol Obstet 2005, 271:46-52

12. Divon MY, Guidetti DA, Braverman JJ, Oberlander E, Langer O, Merkatz IR: Intrauterine growth retardation-a prospective study of the diagnostic value of real-time sonography combined with umbilical artery flow velocimetry. Obstet Gynecol 1988, 72:611-614.

13. Newnham JP, Patterson LL, James IR, Diepeveen DA, Reid SE: An evaluation of the efficacy of doppler flow velocity waveform analysis as a screening test in pregnancy. Am J Obstet Gynecol 1990, 162:403-410.

14. Cruz-Martinez R, Figueras F: The role of doppler and placental screening. Best Pract Res Clin Obstet Gynaecol 2009, 23:845-855.

15. Skotnicki MZ, Flig E, Urban J, Hermann T: Doppler examinations in the prognosis of birth status of the newborn. Med Sci Monit 2000, 6:611-615.

16. Brown MA, Lindheimer MD, Swiet M, Assche AV, Moutquin JM: The classification and diagnosis of the hypertensive disorders of pregnancy: statement from the international society for the study of hypertension in pregnancy (ISSHP). Hypertens Pregnancy 2001, 20:9-14.

17. Sd S: Prevención, diagnóstico y manejo de la preeclampsialeclampsia. 4th edition. Centro Nacional de Equidad de Género y Salud Reproductiva: México; 2007.

18. Detti L, Akiyama M, Mari G: Doppler blood flow in obstetrics. Curr Opin Obstet Gynecol 2002, 14:587-593.

19. Harman CR, Baschat AA: Comprehensive assessment of fetal wellbeing: which doppler tests should be performed? Curr Opin Obstet Gynecol 2003, 15:147-157.

20. Francesc F, Eva M, Gómez O: Vasos e índices de la exploración básica: arterias uterinas, umbilical y cerebral media, Doppler en medicina fetal técnica y aplicación clínica: volume 1. Editorial Medica Panamericana; 2010:35-48.

21. Gomez O, Figueras F, Fernandez S, Bennasar M, Martinez JM, Puerto B, Gratacos E: Reference ranges for uterine artery mean pulsatility index at 11-41 weeks of gestation. Ultrasound Obstet Gynecol 2008, 32:128-132.

22. Mukhopadhyay A, Sharma P, Dasgupta S, Sharma PP, Ghosh TK: Prediction of pre-eclampsia: comparative analysis of two screening tests. J Indian Med Assoc 2012, 110:546-547.

23. Papageorghiou AT, Yu CK, Cicero S, Bower S, Nicolaides KH: Second-trimester uterine artery doppler screening in unselected populations: a review. J Matern Fetal Neonatal Med 2002, 12:78-88.

24. North RA, Ferrier C, Long D, Townend K, Kincaid-Smith P: Uterine artery doppler flow velocity waveforms in the second trimester for the prediction of preeclampsia and fetal growth retardation. Obstet Gynecol 1994, 83:378-386.

25. Gomez O, Figueras F, Martinez JM, del Rio M, Palacio M, Eixarch E, Puerto B, Coll O, Cararach V, Vanrell JA: Sequential changes in uterine artery blood flow pattern between the first and second trimesters of gestation in relation to pregnancy outcome. Ultrasound Obstet Gynecol 2006, 28:802-808.

26. Bower S, Vyas S, Campbell S, Nicolaides KH: Color doppler imaging of the uterine artery in pregnancy: normal ranges of impedance to blood flow, mean velocity and volume of flow. Ultrasound Obstet Gynecol 1992, 2:261-265.

27. Konje JC, Kaufmann P, Bell SC, Taylor DJ: A longitudinal study of quantitative uterine blood flow with the use of color power angiography in appropriate for gestational age pregnancies. Am J Obstet Gynecol 2001, 185:608-613.

28. Trudinger BJ, Giles WB, Cook CM: Uteroplacental blood flow velocity-time waveforms in normal and complicated pregnancy. Br J Obstet Gynaecol 1985, 92:39-45.

29. Trudinger BJ, Giles WB, Cook CM, Bombardieri J, Collins L: Fetal umbilical artery flow velocity waveforms and placental resistance: clinical significance. Br J Obstet Gynaecol 1985, 92:23-30.

30. Aardema MW, Oosterhof H, Timmer A, van Rooy I, Aarnoudse JG: Uterine artery doppler flow and uteroplacental vascular pathology in normal pregnancies and pregnancies complicated by pre-eclampsia and small for gestational age fetuses. Placenta 2001, 22:405-411.
31. Myatt L, Clifton RG, Roberts JM, Spong CY, Hauth JC, Varner MW, Wapner RJ, Thorp JM Jr, Mercer BM, Grobman WA, et al: The utility of uterine artery doppler velocimetry in prediction of preeclampsia in a low-risk population. Obstet Gynecol 2012, 120:815-822.

32. Meizner I, Katz M, Lunenfeld E, Insler V: Umbilical and uterine flow velocity waveforms in pregnancies complicated by major fetal anomalies. Prenat Diagn 1987, 7:491-496.

33. Viero S, Chaddha V, Alkazaleh F, Simchen MJ, Malik A, Kelly E, Windrim R, Kingdom JC: Prognostic value of placental ultrasound in pregnancies complicated by absent end-diastolic flow velocity in the umbilical arteries. Placenta 2004, 25:735-741.

34. Molvarec A, Gullai N, Stenczer B, Fugedi G, Nagy B, Rigo J Jr: Comparison of placental growth factor and fetal flow doppler ultrasonography to identify fetal adverse outcomes in women with hypertensive disorders of pregnancy: an observational study. BMC Pregnancy Childbirth 2013, 13:161

35. Tannirandorn $Y$, Witoonpanich $P$, Phaosavasdi S: Doppler umbilical artery flow velocity waveforms in pregnancies complicated by major fetal malformations. J Med Assoc Thai 1993, 76:494-500.

36. Espinoza J, Romero R, Nien JK, Gomez R, Kusanovic JP, Goncalves LF, Medina L, Edwin S, Hassan S, Carstens M, Gonzalez R: Identification of patients at risk for early onset and/or severe preeclampsia with the use of uterine artery doppler velocimetry and placental growth factor. Am J Obstet Gynecol 2007, 196:326. e321-313.

37. Sibai BM, Gordon T, Thom E, Caritis SN, Klebanoff M, McNellis D, Paul RH: Risk factors for preeclampsia in healthy nulliparous women: a prospective multicenter study: the national institute of child health and human development network of maternal-fetal medicine units. Am J Obstet Gynecol 1995, 172:642-648

38. Duckitt K, Harrington D: Risk factors for pre-eclampsia at antenatal booking: systematic review of controlled studies. BMJ 2005, 330:565.

39. Kaaja R: Predictors and risk factors of pre-eclampsia. Minerva Ginecol 2008, 60:421-429.

40. Park YW, Cho JS, Choi HM, Kim TY, Lee SH, Yu JK, Kim JW: Clinical significance of early diastolic notch depth: uterine artery doppler velocimetry in the third trimester. Am J Obstet Gynecol 2000, 182:1204-1209.

41. Park YW, Lim JC, Kim YH, Kwon HS: Uterine artery doppler velocimetry during mid-second trimester to predict complications of pregnancy based on unilateral or bilateral abnormalities. Yonsei Med J 2005, 46:652-657.

42. Divon MY, Ferber A: Umbilical artery doppler velocimetry-an update. Semin Perinatol 2001, 25:44-47.

43. Westergaard HB, Langhoff-Roos J, Lingman G, Marsal K, Kreiner S: A critical appraisal of the use of umbilical artery doppler ultrasound in high-risk pregnancies: use of meta-analyses in evidence-based obstetrics. Ultrasound Obstet Gynecol 2001, 17:466-476.

44. Bahlmann F, Reinhard I, Krummenauer F, Neubert S, Macchiella D, Wellek S: Blood flow velocity waveforms of the fetal middle cerebral artery in a normal population: reference values from 18 weeks to 42 weeks of gestation. J Perinat Med 2002, 30:490-501.

45. Ebbing C, Rasmussen S, Kiserud T: Middle cerebral artery blood flow velocities and pulsatility index and the cerebroplacental pulsatility ratio: longitudinal reference ranges and terms for serial measurements. Ultrasound Obstet Gynecol 2007, 30:287-296.

doi:10.1186/1756-0500-6-477

Cite this article as: Lopez-Mendez et al:: Doppler ultrasound evaluation in preeclampsia. BMC Research Notes 2013 6:477. 